\title{
Cytological phenotypes of spontaneous sputum in the assessment of the presence and type of bronchopulmonary inflammation in patients with asthma and chronic obstructive pulmonary disease
}

\begin{abstract}
This study was done in order to determine the cellular phenotypes of spontaneous sputum, and to evaluate the features of respiratory inflammation based on sputum cytology results. The study looked at 72 patients, with 23 patients having moderate asthma in combination with chronic bronchitis (asthma $+\mathrm{CB}), 18$ patients having moderate asthma in combination with chronic obstructive pulmonary disease (asthma $+\mathrm{COPD}$ ), and 31 patients having only COPD. All patients were studied during a period of disease exacerbation and had a productive cough. Eosinophilic, neutrophilic, epithelial and macrophagic phenotypes were determined. Mono cellular phenotypes were rare, with patients with asthma and COPD having a predominantly multi cellular phenotype.

It is widely accepted and confirmed in international statements (GINA, GOLD) that broncho pulmonary inflammation is involved in the pathogenesis of asthma and chronic obstructive pulmonary disease (COPD). For this reason, doctors and researchers are interested in studying sputum, which is a product of the respiratory tract.
\end{abstract}

Volume 2 Issue I - 2015

Fedoseev GB, Trofimov VI,Timchik BG, Negrutsa KV, Gorovneva EV, Rogachevskaya NN, Razumovskaya TS, Aleksandrin VA, Golubeva VI, Filippova NA, Birulya IV, Kryakunov KN

Faculty of Hospital Medicine, Pavlov First State Medical University of Saint Petersburg, Russia

Correspondence: Fedoseev GB, Faculty of Hospital Medicine, Pavlov First State Medical University of Saint Petersburg, Petrograd, Russia, Tel +7 92 I-91 I-90-32, 499-7I-88, 91 I-90-32, 346-39-45, Email fedoseevsp@mail.ru

Received: November 05, 2014 | Published: January 17, 2015

Keywords: asthma, chronic obstructive pulmonary disease, chronic bronchitis, sputum, sputum cellular phenotypes, inflammation

\section{Methods of obtaining sputum}

In patients with asthma, when it is combined with chronic bronchitis (CB) and COPD, and in patients with COPD, coughing is often accompanied by the production of sputum. Certainly spontaneously produced sputum is investigated in these cases. ${ }^{1}$ However, many patients with chronic inflammatory lung disease do not spontaneously produce sputum, ${ }^{2}$ so that induced sputum is studied in these cases. In 1989, Gibson et al., ${ }^{3}$ developed a method of obtaining sputum, based on the inhalation of a hypertonic saline solution. They used a hypertonic solution $(4.5 \%$ for patients in remission and $0.9 \%$ for patients with disease exacerbation), which was delivered to the patient via a nebuliser. Samples of the expectorated sputum were processed and used in cytology and other studies. Sputum induction was successful in $90 \%$ of patients. ${ }^{4}$ The cytology results of spontaneous and induced sputum samples turned out to be identical. ${ }^{5}$

The goal of sputum induction is to collect a sufficient amount of mucus from the lower airways, in patients, who do not spontaneously produce sputum, in order to study the features of inflammation in asthma and other respiratory conditions. ${ }^{6}$ Induced sputum cytology is considered a gold standard for identifying the inflammatory phenotype in patients with asthma. ${ }^{7}$ However, spontaneous sputum is considered preferable in clinical practice, ${ }^{8}$ so in cases where the patient produces sputum, it is the spontaneously produced sputum that is studied.

The advantages of studying induced sputum have been evaluated by a number of authors. ${ }^{910}$ Cell viability is higher in induced sputum than in spontaneous sputum. The lengthy presence of mucus in the airways may lead to a reduction in the number of viable cells, while sputum induction leads to the mobilisation of a new cell population. ${ }^{5}$ The method of obtaining induced sputum is not without its disadvantages. The inhalation of hypertonic saline causes bronchospasm in some patients, which is related to the activation of mast cells and the irritation of the respiratory sensory nerves. ${ }^{11}$ The majority of researchers use short-acting $\beta 2$-agonists to avoid bronchospasm in the study patients during the procedure. ${ }^{12}$ One important limitation of this method of inducing sputum is that it is labour intensive, which limits its widespread use in medical practice. ${ }^{13}$

Cytology is one of the main methods of studying sputum, and involves a sputum cell count and the creation of a cytogram, which contains the percentage composition of each cell type. Numerous studies have produced the idea of four cellular phenotypes of sputum cell counts:
i. Eosinophilic ( $\geq 2 \%$ eosinophils)
ii. Neutrophilic ( $\geq 61 \%$ neutrophils)
iii. Mixed
iv. Non-eosinophilic ( $<2 \%$ eosinophils) and non-neutrophilic $(<61 \%$ neutrophils), which has been called paucigranulocytic

\section{The cellular phenotype of sputum from patients with} asthma

Eosinophilic sputum phenotype: The eosinophilic phenotype is most commonly related to atopic asthma and a positive response to treatment with inhaled corticosteroids. ${ }^{14}$ In adult patients with asthma, not treated with inhaled corticosteroids, $22 \%$ demonstrated 
consistent eosinophilia in their sputum, $31 \%$ of patients had periodical eosinophilia in their sputum, and $47 \%$ of patients had a consistently low eosinophilic cell count $(<2 \%) .{ }^{15}$ Previous studies confirm the high prognostic sensitivity of measuring the eosinophilic content in sputum, since an increase in the number of eosinophils precedes an asthma exacerbation, ${ }^{16}$ and the eosinophilic phenotype is commonly found in patients with asthma, who react well to treatment with corticosteroids ${ }^{7}$ and anti-IL-5 therapy. ${ }^{17}$ A low eosinophilic sputum count is noted in patients with asthma, who demonstrate a reduced response to treatment with corticosteroids. ${ }^{16}$ On the other hand, the presence of sputum eosinophilia does not always correspond to mild asthma or to successful treatment with corticosteroids, ${ }^{18}$ and the belief that controlling the number of eosinophils in the sputum will ensure high treatment effectiveness is not always supported by the research. ${ }^{19}$ The lack of a positive treatment response in patients with the eosinophilic phenotype, despite the administration of corticosteroids, is thought to be related to the remodelling of the airways, and is a poor prognostic indicator in these patients. ${ }^{20}$

Neutrophilic sputum phenotype: The neutrophilic sputum phenotype is present in $59 \%$ of adult patients with asthma. ${ }^{21}$ During an asthma exacerbation, the eosinophilic phenotype predominates in children, and the neutrophilic phenotype is more common in adults. Some authors believe that the presence of the neutrophilic phenotype is an indicator of more severe asthma. ${ }^{22}$ The neutrophilic inflammatory phenotype is associated with activated neutrophil products such as neutrophil elastase, $\alpha 1$-antitrypsin, interleukins 8 and 17 , and others. ${ }^{23}$ These patients tend to have a poor response to treatment with corticosteroids. ${ }^{24}$ The fact that patients with severe asthma have a predominantly neutrophilic inflammatory phenotype has been noted by many researchers. ${ }^{25,26}$ Moreover, it has been noted that approximately half of patients with mild and moderate asthma have a neutrophilic inflammatory phenotype. ${ }^{15}$

The neutrophilic inflammatory phenotype is often linked to viral respiratory infections, since $70 \%$ of patients with asthma and a viral respiratory infection had a neutrophilic sputum phenotype. ${ }^{27}$ Viruses stimulate bacterial infection activity, which persists in the patients airways. Bacteria stimulate the immune response via the liberation of pro-inflammatory cytokines, such as IL-8 and TNF, and can induce neutrophilic inflammation. ${ }^{28}$ Chlamydophila pneumonia is often considered one of the causes of neutrophilic inflammation in patients with asthma. ${ }^{29}$ But not all authors confirm the role of Chlamydophila pneumonia as the cause of neutrophilic inflammation. ${ }^{30}$ There is discussion about neutrophilic bronchitis, present in $10 \%$ of asthma patients, which is characterised by neutrophilic inflammation, and a severe, incurable disease course. The accumulation of neutrophils in the airways is linked to increased chemotaxis and active migration into the lungs. Moreover, neutrophils may block pulmonary micro vessels due to their low elasticity. This leads to a higher concentration of neutrophils in the area of inflammation. ${ }^{31}$

Excessive accumulation of leucocytes in the sputum creates purulent sputum, which is related to a bacterial infection. Mucoid sputum is colourless, while the accumulation of pus is accompanied by colour changes from pale yellow to dark green..$^{32}$ There are a few classification types for assessing sputum:
i. Type 1: Transparent, opaque,
ii. Type 2: Mucopurulent, yellow in colour,
iii. Types 3 and 4: Purulent, green to dark green in colour ${ }^{33}$

The colour of the sputum is related to the presence of neutrophils, activated by the bacterial infection in the respiratory system, as they secrete neutrophil elastase and myeloperoxidase, which gives the sputum its green colour. ${ }^{34,35}$ Information from the patient about colour changes in spontaneously produced sputum from opaque to yellowgreen in the last 72hours is a confirmation of the presence of purulent sputum, most likely due to a bacterial respiratory infection. ${ }^{36}$ Longterm use of clarithromycin is recommended for patients with asthma of the neutrophilic inflammatory phenotype. ${ }^{37}$ The morphological differences of eosinophilic and non-eosinophilic (neutrophilic) asthma phenotypes relate to the formation of subepithelial fibrosis and thickening of the basal membrane ${ }^{38}$ in patients with eosinophilic asthma, and emphysema in patients with neutrophilic asthma. ${ }^{39}$

\section{Paucigranulocytic inflammation phenotype in patients with asthma}

This phenotype is quite common, and is present in approximately $50 \%$ of adults and children with mild and moderate asthma. These patients tend to have well-controlled disease with a favourable course $^{30}$

Inflammatory phenotypes in patients with asthma, according to sputum cytology: Asthma sufferers tended to be more commonly diagnosed with the eosinophilic phenotype, which was associated with non-infectious allergens. According to the data of Schelich et al., ${ }^{7} 41 \%$ of patients with asthma had eosinophilic inflammation, $16 \%$ had neutrophilic, $3 \%$ had mixed, and $40 \%$ had a paucigranulocytic phenotype. Mohamed et al., ${ }^{40}$ provide similar results: $63.8 \%$ had eosinophilic inflammation, $10 \%$ had neutrophilic, $10 \%$ had mixed, and $26.2 \%$ had a paucigranulocytic inflammatory phenotype, but the authors stress that the degree of control over treatment effectiveness does not relate to the inflammatory phenotype. A significant proportion of adults and children with difficult-to-treat asthma and wheezing, have neutrophilic inflammation. ${ }^{41}$

During an asthma exacerbation, adults demonstrate a neutrophilic phenotype, and an eosinophilic phenotype during remission. ${ }^{42}$ An increase in the number of eosinophils in the sputum correlates to an increase in asthma severity, while a reduction correlates with an improvement in the condition. This had led to the eosinophil content being considered a marker of asthma severity. ${ }^{43}$ It has been established that the eosinophilic inflammatory phenotype is an indicator of a good response to treatment. ${ }^{44,45}$

change in the inflammatory phenotype occurs quite often. $41 \%$ of children with asthma showed a change from the neutrophilic phenotype to the eosinophilic phenotype, when monitored over time. There is instability in the inflammatory phenotype of children with asthma of any degree of severity. ${ }^{46}$ After 12 weeks of treatment with placebo, $80 \%$ of patients had a change from the neutrophilic phenotype to the eosinophilic phenotype without any clear cause. It is likely that is due to the effect of external factors, such as allergens, seasonal changes, ecological factors and respiratory infections. ${ }^{47}$ The percentage of eosinophils in the sputum decreases with ongoing corticosteroid treatment. ${ }^{48}$ The clearly demonstrated change in the cellular content of induced sputum allowed Hencox et al., ${ }^{49}$ to draw two conclusions:

i. The eosinophilic and neutrophilic versions of a sputum cytogram are likely to characterise disease severity, rather than the inflammatory phenotype. 
ii. The eosinophilic or neutrophilic nature of inflammation in a particular patient can be determined only with repeat studies over time ${ }^{49}$

patient may have several cellular inflammatory phenotypes. One study noted that $63 \%$ of children with asthma had two or even three inflammatory phenotypes simultaneously. ${ }^{46}$

Inflammatory phenotypes in patients with COPD: To determine the inflammatory phenotype in patients with COPD, a cytology analysis of spontaneous sputum, and the results of viral and bacterial analyses were used. Three phenotypes were described, which received the name 'clinical phenotypes': bacterial (with a predominance of bacteria), viral (with a predominance of viruses) and eosinophilic (with a high percentage of eosinophils in the sputum cytogram). ${ }^{50}$

A cluster analysis of inflammatory phenotypes in patients with COPD confirmed the presence of the clinical phenotypes: bacterial, viral, eosinophilic, and added a fourth phenotype, which was called pauciinflammatory. It was noted that the use of these phenotypes will enable the prescription of individual treatment, taking into account the specifics of COPD progression. ${ }^{51}$

\section{Materials and methods}

The study included 72 patients, with group 1 consisting of 23 people (6 men, 17 women, mean age $46.5 \pm 17.04$ years) with moderate asthma in combination with chronic bronchitis (CB), group 2 consisting of 18 people (14 men and 4 women, mean age $57.3 \pm 10.6$ years) with moderate asthma in combination with COPD, and group 3 consisting of 31 people ( 23 men and 8 women, mean age $62.8+/-8.39$ years) with COPD. All subjects with moderate asthma had an infection-dependent asthma phenotype, which was combined with the atopic phenotype in $83 \%$. All patients were assessed during an asthma exacerbation, and all patients had a productive cough.

General clinical, laboratory and instrumental investigations were carried out, which included functional respiratory studies. Morning sputum was collected and a native, haematoxylin - and eosin - stained specimen underwent cytology. Cellular components were counted in 20 fields. 200-300 cells were counted and a cytogram created, which displayed the percentage composition of every type of cell: bronchial epithelium, macrophages and leucocytes (neutrophils, eosinophils, lymphocytes, monocytes). The cytology analysis was done using the mean percentage composition of a particular cell.

The fractional exhaled nitric oxide (FENO) level was also calculated. FENO measurement in ppb was done using the NO breath device (Bedfont Scientific Ltd, Great Britain). The program STATISTICA 6.1 by Stat Soft, Inc. was used for statistical data analysis. For statistically significantly results, $\mathrm{p}<0.05$ was considered significant. For descriptive statistics of quantitative measures, mean and standard deviation scores were used $(\mathrm{M} \pm \mathrm{s})$. Student's T-test and Pearson's correlation analysis was also used.

\section{Results and discussion}

\section{The cytological characteristics of sputum in the study patients}

The mean percentage indicators shown in Table 1 of the different cells present in the sputum cytogram of the study patients indicate a weak statistical trend towards an increased neutrophil content in the sputum of patients with COPD and eosinophil content in patients with asthma $+\mathrm{CB}$. In order to determine the manifestation rate of the various cells present in the sputum, taking into consideration the distribution curve, three value levels were determined: low, medium and high (Table 2). High cell content in the sputum can thus indicate a cellular phenotype in a particular patient.

\section{Cytological disease phenotypes according to high cell content in the sputum}

Figure 1 shows the percentage of patients in the study groups, with a high cell content in their sputum.

Patients in group 1 (asthma $+\mathrm{CB}$ ) had a predominantly eosinophilic phenotype $(56 \%)$, with only $7 \%$ of patients having a monocellular eosinophilic phenotype. The eosinophilic phenotype was seen nearly three times less frequently (19\%) in patients in group 3 (COPD), with only $10 \%$ having a monocellular eosinophilic phenotype. The neutrophilic phenotype predominated in patients in group $3(42 \%)$, with $12 \%$ of patients having the monocellular variant. The neutrophilic phenotype was 1.5 times less frequent in patients in group 1.

Table I Sputum cytograms in patients with moderate asthma $+\mathrm{CB}$, moderate asthma + COPD, and only COPD

\begin{tabular}{|c|c|c|c|c|c|c|}
\hline \multirow{2}{*}{ Cells } & \multicolumn{2}{|c|}{ Asthma + CB (23) } & \multicolumn{2}{|c|}{ Asthma + COPD (18) } & \multicolumn{2}{|c|}{ COPD (3I) } \\
\hline & $\mathbf{M}$ & m & $M$ & $\mathbf{m}$ & $M$ & $\mathbf{m}$ \\
\hline Neutrophiles & 35.96 & 11.67 & 36.61 & 14.22 & 42.81 & 15.56 \\
\hline Eosinophiles & 20.52 & 8.19 & 18.00 & 10.39 & 13.90 & 10.45 \\
\hline Macrophiles & 25.13 & 13.09 & 26.67 & 14.29 & 23.06 & 11.28 \\
\hline Lymphocytes & 7.39 & 3.24 & 7.00 & 3.65 & 9.16 & 3.77 \\
\hline Monocytes & $\mathrm{I} .04$ & 1.18 & 1.89 & 2.97 & 2.09 & 2.44 \\
\hline Epithelium & 9.95 & 9.15 & 9.83 & 10.24 & 8.97 & 8.17 \\
\hline
\end{tabular}

Citation: Fedoseev GB, Trofimov VI,Timchik BG, et al. Cytological phenotypes of spontaneous sputum in the assessment of the presence and type of bronchopulmonary inflammation in patients with asthma and chronic obstructive pulmonary disease.J Lung Pulm Respir Res. 20I5;2(I):I0-I5. DOI: 10.15406/jlprr.2015.02.00029 


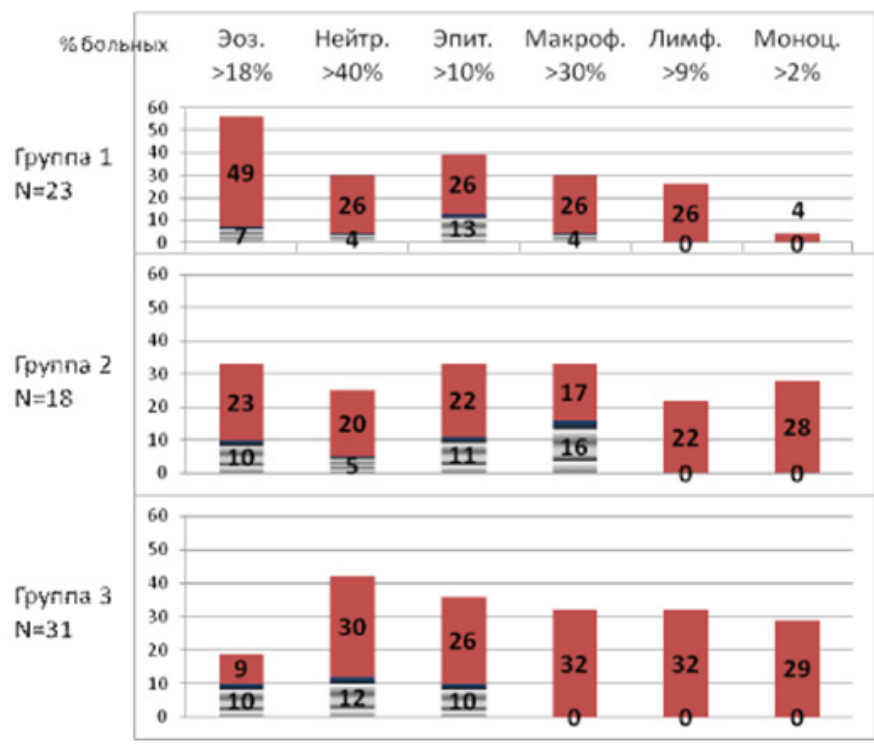

Figure I Percentage of patients in the study groups, with a high cell content in their sputum.

Table 2 Reference levels of the various cells present in the sputum (in \%)

\begin{tabular}{llll}
\hline Sputum cells & Low & Medium & High \\
\hline Neutrophils & $\leq 30$ & $31-40$ & $>40$ \\
Eosinophils & $\leq 12$ & $13-18$ & $>18$ \\
Macrophages & $\leq 20$ & $21-30$ & $>30$ \\
Lymphocytes & $\geq 6$ & $7-9$ & $>9$ \\
Monocytes & 0 & 2 & $>2$ \\
Epithelium & $\leq 3$ & $4-10$ & $<10$ \\
\hline
\end{tabular}

The second patient group (asthma+COPD) demonstrated a cellular phenotype that was intermediate between the values in group 1 and the values in group 3. Special attention should be paid to the epithelial phenotype, previously undescribed in the literature, which characterises the degree of damage of the bronchial epithelium, and the macrophagial phenotype, which reflects the degree of defence.
These phenotypes were present to an equal degree in patients in all three groups, in approximately $30 \%$ of patients and predominantly in combination with other cellular phenotypes. In $20-30 \%$ of patients, maximal numbers of lymphocytes and monocytes were present in the sputum, always in combination with high levels of other cells. 15 out of 23 patients in group $1(65 \%)$ had a combination of several cellular phenotypes (10 combinations), 10 out of 18 patients in group $2(55 \%)$ had a combination of several cellular phenotypes (9 combinations), and 22 out of 31 patients in group $3(71 \%)$ had a combination of several cellular phenotypes ( 13 combinations).

A cytology analysis of the maximal percentage of cells in the patient's sputum allows the following conclusions to be drawn:

i. Apart from the eosinophilic and neutrophilic phenotypes, there exist also the epithelial and macrophagic phenotypes

ii. Monocellular sputum phenotypes are rare in cytology, being present in only $4-16 \%$ of patients

iii. There is a high number of cellular combinations in multicellular sputum cytograms

iv. Patients with asthma $+\mathrm{CB}$ have a predominantly eosinophilic sputum phenotype (56\% of patients), while patients with COPD have a predominantly neutrophilic sputum phenotype ( $42 \%$ of patients)

The results of comparing the percentage composition of eosinophils and neutrophils in the peripheral blood and in sputum

Figure 2 shows the results of comparing the percentage composition of eosinophils and neutrophils in the sputum and in the peripheral blood of the study subjects, without separating them into clinical groups.

The correlation between the percentage of eosinophils and neutrophils in sputum and in the peripheral blood of patients with asthma $+\mathrm{CB}$, asthma $+\mathrm{COPD}$, and COPD. The comparison showed a strong, direct correlation $(r=0.3454 ; \mathrm{p}=0.0011)$ between the content of eosinophils in the blood and in the sputum, which corresponds to information in the literature. ${ }^{18}$ It is likely that the control of eosinophil numbers in the sputum and in the blood is done on a systemic level. There was no correlation between the neutrophil numbers in the blood and in the sputum. This is due to the fact that control of neutrophil numbers in the sputum occurs directly in the bronchi and the lungs. These results correspond to data in previously published literature. ${ }^{7}$
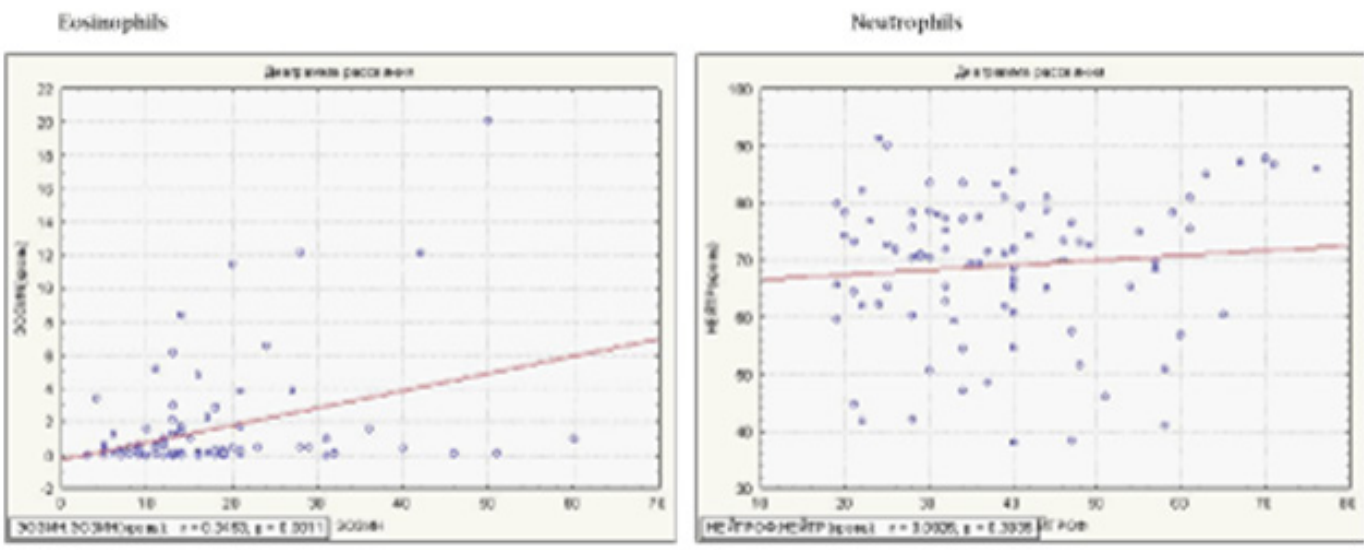

Figure 2 Results of comparing the percentage composition of eosinophils and neutrophils in the sputum and in the peripheral blood of the study subjects, without separating them into clinical groups. 


\section{The results of comparing the percentage composition of eosinophils and macrophages in sputum}

Due to finding eosinophilic apoptosis matter in the macrophages present in the sputum of asthma patients, the correlation between eosinophils and macrophages in patients with asthma $+\mathrm{CB}$ was considered to be of interest. It was found that there is an inverse and statistically significant correlation between eosinophils and macrophages in the sputum of patients with asthma+CB. These results, to a certain extent, support the controlling function that macrophages play in relation to eosinophils (Figure 3).

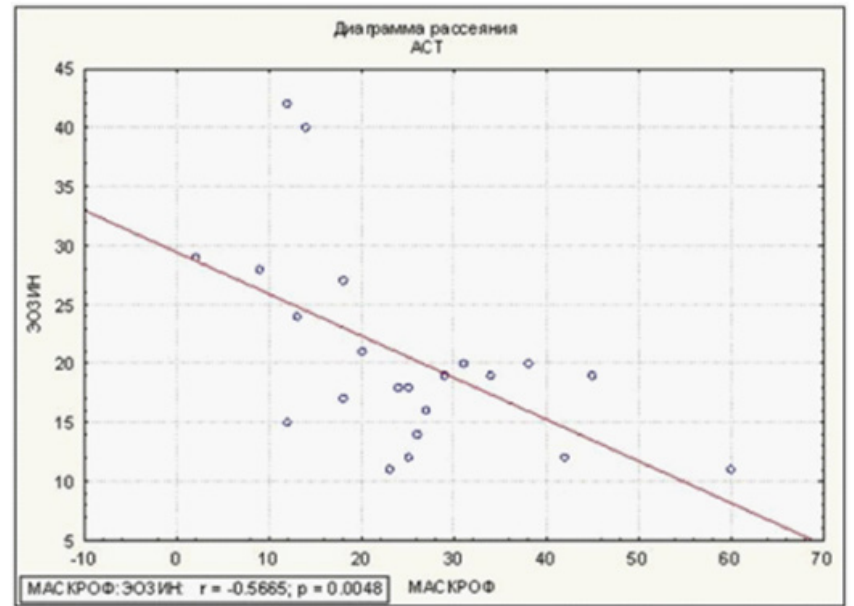

Figure 3 The correlation between macrophages and eosinophils in the sputum of patients with asthma $+C B$.

\section{Conclusion}

1. The cytological phenotypes of spontaneous sputum in the study subjects have the following features:

i. Apart from the eosinophilic and neutrophilic phenotypes, there are also epithelial and macrophagic phenotypes

ii. Monocellular phenotypes occur in $4-16 \%$ of patients with different conditions and this is true for different cell types

iii. There is a large number of cell combinations in the sputum cytograms of multicellular phenotypes

iv. Patients with asthma $+\mathrm{CB}$ have a predominantly eosinophilic phenotype, while patients with COPD have a predominantly neutrophilic phenotype

2. There is a significant direct correlation between the number of eosinophils in the sputum and in the blood, which is likely due to systemic regulation. There is no correlation between the number of neutrophils in the blood and in the sputum, likely because of the predominantly local control of these indicators.

There is a statistically significant inverse correlation between the number of macrophages and eosinophils in sputum.

\section{Summary}

This study was done in order to determine the cellular phenotypes of spontaneous sputum, and to evaluate the features of respiratory inflammation based on sputum cytology results. The study looked at 72 patients, with 23 patients having moderate asthma in combination with chronic bronchitis (asthma $+\mathrm{CB}$ ), 18 patients having moderate asthma in combination with chronic obstructive pulmonary disease (asthma $+\mathrm{COPD}$ ), and 31 patients having only COPD. All patients were studied during a period of disease exacerbation and had a productive cough. Eosinophilic, neutrophilic, epithelial and macrophagic phenotypes were determined. Monocellular phenotypes were rare, with patients with asthma and COPD having a predominantly multicellular phenotype.

\section{Acknowledgements}

None.

\section{Conflict of interest}

The author declares no conflict of interest.

\section{References}

1. Soler N, Esperatti M, Ewig S, et al. Sputum purulence-guided antibiotic use in hospitalized patients with exacerbations of COPD. Eur Respir J. 2012;40(6):1344-1353.

2. Preto L. Induced sputum as a method for the study of bronchial inflammation. Arch Broncopneumol. 2011;47(7):323-324.

3. Gibson PG, Girgis-Gabardo A, Morris MM, et al. Cellular characteristics of sputum from patients with asthma and chronic bronchitis. Thorax. 1989;44(9):689-692.

4. Nezar R Mohameda, Elham A Abdel Ghany, et al. Analysis of induced sputum in patients with bronchial asthma. Egyptian Journal of Chest Diseases and Tuberculosis. 2014;63(1):21-27.

5. Bhowmik A, Seemunga TA, Sapsford RJ, et al. Comparison of spontaneous and induced sputum for investigation of airway inflammation in chronic obstructive pulmonary disease. Thorax. 1998;53(11):953-956.

6. Paggiaro PL, Chanez P, Holz O, et al. Sputum induction. Eur Respir J. 2002;20 (Suppl 37):3s-8s.

7. Schleich FN, Manise M, Sele J, et al. Distribution of sputum cellular phenotype in a large asthma cohort: predicting factors for eosinophilic vs neutrophilic inflammation. BMC Pulm Med. 2013;13:11.

8. Zock JP, Vizcaya D, Le Moual N. Update in asthma 2008. Am J Respir Crit Care Med. 2009;179(10):869-874.

9. Jayaram L, Pizzichini MM, Cook RJ, et al. Determining asthma treatment by monitoring sputum cell counts: effect on exacerbations. Eur Respir J. 2006;27(3):483-494.

10. Chlumsky J, Striz I, Terl M, et al. Strategy aimed at reucion of sputum eosinophils decreases exacerbation rate in patients with asthma. $J$ Int Med Res. 2006;34(2):129-139.

11. Makker HK, Holgate ST. The contribution of neurogenic reflexes to hypertonic saline-induced bronchoconstriction in asthma. J Allergy Clin Immunol. 1993;92(1 Pt 1):82-88.

12. Keatings VM, Barnes PJ. Granulocyte activation marekers in induced sputum: comparison between chronic obstructive pulmonary disease, asthma and normal subjects. Am J Respir Crit Care Med. 1997;155(2):449-453.

13. Prieto L. Induced sputum as a method for the study of bronchial inflammation. Arch Broconeumol. 2011;47(7):323-324.

14. Berry M, Morgan A, Shaw DE, et al. Pathlogical features and inhaled corticosteroid response of eosinophilic and non-eosinophilic asthma. Thorax. 2007;62(12):1043-1049. 
15. McGrath KW, Icitovic N, Boushey HA, et al. A large subgroup of mildto-moderate asthma is persistently noneosinophilic. Am J Respir Crit Care Med. 2012;185(6):612-619.

16. Leuppi JD, Salome CM, Jenkins CR, et al. Markers of airway inflammation and hyper responsiveness in patients with well-controlled asthma. Eur Respir J. 2001;18(3):444-450.

17. Parameswaran Nair. What is an "eosinophilic phenotype" of asthma? $J$ Allergy Clin Immunol. 2013;132(1):81-83.

18. Bartoli ML, Bacci E, Carnevali S, et al. Clinical assessment of asthma severity partially corresponds to sputum eosinophilic airway inflammation. Respiratory Med. 2004;98(2):184-193.

19. Fleming L, Wilson N, Regamey N, et al. Use of sputum eosinophil counts to guide management in children with severe asthma. Thorax. 2012;67(3):193-198.

20. Fabbri LM, Romagnoli M, Corbetta L, et al. Differences in airway inflammation in patients with fixed airflow obstruction due to asthma or chronic obstructive pulmonary disease. Am J Respir Crit Care Med. $2003 ; 167(3): 418-423$

21. Gibson PG, Simpson JL, Saltos N. Heterogeneity of airway inflammation in persistent asthma evidence of neutrophilic inflammation and increased sputum interleukin-8. Chest. 2001;119(5):1329-1336.

22. Telenga ED, Tideman SW, Kerstjens HA, et al. Obesity in asthma:more neutrophilic inflammation as a possible explanation for a reduced treatment response. Allergy. 2012;67(8):1060-1068.

23. Фомина ДС, Дробик ОС, Горячкина ЛА. Фенотипирование бронхиальной астмы с элементами эндотипирования:перспективы развития направления. Consilium medicum. 2012;11:15-18.

24. Fomina DS, Drobik OS, Goryachkina LA. Phenotypic testing of bronchial asthma with elements of annotirovanyy:prospects of development direction. Consilium medicum. 2012;11:15-18 (in Russian).

25. Fahy JV. Eosinophilic and neutophilic inflammation in asthma:Insights from clinical studies. Proc Am Thorac Soc. 2009;6(3):256-259.

26. Jatakanon A, Uasuf C, Maziak W, et al. Neutrophilic inflammation in severe persistent asthma. Am J Respir Crit Care Med. 1999;160(5 Pt 1):1532-1539.

27. G Hoskins, C McCowan, Neville RG, et al. Risk factors and costs associated with an asthma attack. Thorax. 2000;55(1):19-24.

28. Wark PA, Johnston SL, Moric I, et al. Neutrophil degranulation and cell lysis is associated with clinical severity in virus-induced asthma. Eur Respir J. 2002;19(1):68-75.

29. Qingling Zhang, Rowland Illing, Christopher K Hui, et al. Bacteria in sputum of stable severe asthma and increased airway wall thickness. Respiratory Research. 2012;13:35.

30. Horvat JC, Starkey MR, Kim RY, et al. Chlamydial respiratory infection during allergen sensitization drives neutrophilic allergic airways disease. J Immunol. 2010;184(8):4159-4169.

31. Wang F, He XY, Baines KJ, et al. Different inflammatory phenotypes in adults and children with acute asthma. Eur Resp J. 2011;38(3):567-574.

32. Shirai A. Modeling neutrophil transport in pulmonary capillaries. Respir Physiol Neurobiol. 2008;163(1-3):158-165.

33. Soler N, Torres A. Significance of sputum purulence to guide antibiotic therapy in exacerbations of COPD. Eur Respir J. 2013;41(1):248-249.

34. Murray MP, Pentland JL, Turnbull K, et al. Sputum colour: a useful clinical tool in non-cystic fibrosis bronchiectasis. Eur Respir $J$. 2009;34(2):361-364.
35. Deepak Aggarwal, Prasanta R Mohapatra, Phiza Aggarwal P. Significance of sputum purulence to guide antibiotic therapy in exacerbations of COPD. Eur Respir J. 2013;41(1):248-249.

36. Stockley RA, Bayley D, Hill SL, et al. Assessment of airway neutrophils by sputum colour: correlation with airways inflammation. Thorax. 2001;56(5):366-372.

37. Stockley RA, O Brien C, Pye A, et al. Relationship of sputum color to nature and outpatient management of acute exacerbations of COPD. Chest. 20000;117(6):1638-1645.

38. Simpson JL, Powell H, Boyle MJ, et al. Clarithromycin targets neutrophilic airway inflammation in refractory asthma. Am J Respir Crit Care Med. 2008;177(2):148-155.

39. Fahy JV. Eosinophilic and neutrophilic inflammation in asthma:insight from clinical studies. Proc Am Thorac Soc. 2010;6(3):256-259.

40. Lee BJ, Moon HG, Shin TS, et al. Protective effects of basic fibroblast growth factor in the development of emphysema induced by interferon- . Exp Mol Med. 2011;43(4):169-178.

41. Nezar R Mohameda, Elham A, Abdel Ghanya, et al. Analysis of induced sputum in patients with bronchial asthma. Egyptian Journal of Chest Diseases and Tuberculosis. 2014;63(1):21-27.

42. Li AM, Tsang TWT, Chan DFY, et al. Cough frequency in children with mild asthma correlates with sputum neutrophil count. Thorax. 2006;61(9):747-750.

43. Wang F, He XY, Baines KJ, et al. Different inflammatory phenotypes in adult and children with acute asthma. Eur Respir J. 2011;38(3):567-574.

44. Bandyopadhyay A, Roy PP, Saha K, et al. Usefulness of induced sputum eosinophil count to assess severity and treatment outcome in asthma patients. Lung India. 2013;30(2):117-123.

45. Berry M, Morgan A, Shaw DE, et al. Pathological features and inhaled corticosteroid response of eosinophilic and non-eosinophilic asthma Thorax. 2007;62(12):1043-1049.

46. Haldar P, Brightling CE, Hargadon B, et al. Mepolizumab and exacerbations of refractory eosinophilic asthma. $N$ Engl J Med. 2009;360(10):973-984.

47. Fleming L, Tsartsali L, Wilson N, et al. Sputum inflammatory phenotypes are not stable in children with asthma. Thorax. 2012;67(8):675681.

48. Hancox RJ, Cowan DC, Aldridge RE, et al. Asthma phenotypes: consistency of classification using induced sputum. Respirology. 2012;17(3):461-466.

49. Aldridge RE, Hancox RJ, Robin Taylor D, et al. Effects of terbutaline and budesonide on sputum cells and bronchial hyper responsiveness in asthma. Am J Respir Crit Care Med. 2000;161(5):1459-1464.

50. Hancox RJ, Cowan DC, Aldridge RE, et al. Asthma phenotypes Consistency of classification using induced sputum. Respirology. 2012;17(3):461-466.

51. John R Hurst. Exacerbaton, phenotyping in chronic obstructive pulmonary disease. American Journal of Respiratory and Critical Care Medicine. 2011;184(6):625-626.

52. Hurst JR, Donaldson GC, Perera WR, et al. Use of plasma biomarkers at exacerbation of chronic obstructive pulmonary disease. Am J Respir Crit Care Med. 2006;174(8):867-874.

Citation: Fedoseev GB, Trofimov VI,Timchik BG, et al. Cytological phenotypes of spontaneous sputum in the assessment of the presence and type of bronchopulmonary inflammation in patients with asthma and chronic obstructive pulmonary disease.J Lung Pulm Respir Res. 20I5;2(I):I0-I5. 